\title{
Detection and Monitoring of Greeneria uvicola and Colletotrichum acutatum Development on Grapevines by Real-Time PCR
}

\author{
Suren K. Samuelian, Lindsay A. Greer, Sandra Savocchia, and Christopher C. Steel, National Wine \& Grape Industry Centre,
} Charles Sturt University, Locked Bag 588, Wagga Wagga, NSW 2678, Australia

\begin{abstract}
Samuelian, S. K., Greer, L. A., Savocchia, S., and Steel, C. C. 2011. Detection and monitoring of Greeneria uvicola and Colletotrichum acutatum development on grapevines by real-time PCR. Plant Dis. 95:298-303.

Bitter rot (Greeneria uvicola) and ripe rot (Colletotrichum acutatum, syn. C. simmondsii) occur frequently in subtropical grape-growing regions of Australia, where they cause yield loss and bitter taints in wine. To further advance the epidemiological studies of G. uvicola and C. acutatum and contribute toward their effective management and control, a rapid and reliable species-specific real-time polymerase chain reaction (PCR) method was developed based on the polymorphic portion of the internal transcribed spacer region of the two fungi. It was found that, within 6 to $8 \mathrm{~h}$ postinoculation, the assay could detect

as little as $20 \mathrm{fg}$ of genomic DNA and 10 conidia for both species. Artificially and naturally infected grape inflorescences and mature berries were analyzed by both conventional plating methods and realtime PCR. Fungal presence was demonstrated on all plant material but development was observed only on mature berries. The results demonstrate that the real-time PCR technique is a highly specific, rapid, and sensitive method that can be used to detect and study the dynamics of G. uvicola and C. acutatum during different stages of infection and on different grape tissues.
\end{abstract}

Colletotrichum acutatum (syn. C. simmondsii; 27) and Greeneria uvicola are two fungal pathogens associated with rot of grape bunches in subtropical vineyards. Disease expression of $\mathrm{C}$. $\mathrm{acu}$ tatum involves a discharge of characteristic orange spore masses from the surface of the grape berry, while the symptoms of G. uvicola include black sporulation, often in concentric rings around the berry circumference. Both organisms can occur concurrently in one vineyard and even on one single berry (28). C. acutatum causes ripe rot in grape and a characteristic bitter taint in wine produced from infected grape berries (18). G. uvicola, responsible for the disease bitter rot, also produces bitter taints in grape berries which are transferred to the finished wine. Management of both diseases is hampered by a lack of epidemiological information. The late and rapid development of bunch rots following rainfall and warm conditions close to harvest also limits options for fungicidal control.

In recent years, polymerase chain reaction (PCR)-based methods have emerged as major tools for the diagnosis and study of phytopathogenic fungi and have alleviated some of the problems associated with detection, quantification, and control of a large number of species. These techniques are rapid and less laborious than traditional approaches because isolation of the fungus from the infected tissue is no longer required. The most commonly used methods are standard and real-time PCR, which use specific primers to amplify certain DNA regions. One of the most commonly used DNA regions is the ribosomal DNA (rDNA) internal transcribed spacer 1 (ITS1) region $(3,6,8,10-13,25,26)$. Because the ITS sequence occurs in multiple copies in the genome, the target concentration is effectively increased, thereby increasing its value for diagnostic purposes. Real-time PCR also offers increased sensitivity for detection of low concentrations of DNA and removes the need for post-PCR processing (26). Quantification of the DNA template is achieved by continuous monitoring of the amplification by detection of a threshold cycle $\left(\mathrm{C}_{\mathrm{t}}\right)$ in the early exponential stage of

Corresponding author: S. Samuelian, E-mail: ssamuelian@csu.edu.au

Accepted for publication 1 November 2010.

doi:10.1094/PDIS-07-10-0537

(C) 2011 The American Phytopathological Society the amplification process, and comparison of amplification curves to known standards. This approach provides opportunities to study pathogen movement in various environmental samples, including host tissues, soil, water, and air, opening advanced research opportunities for determination of inoculum threshold levels and elucidation of epidemiology and host-pathogen interactions. Because of its sensitivity, specificity, and reproducibility, real-time PCR is suitable for detection of trace amounts of fungal DNA (10) and differentiation of closely related fungi $(2,4,6,8)$.

Different fungal pathogens can occur concurrently on a grape berry, making conventional identification and diagnosis difficult. The aim of this study was to develop a simple, rapid, and reliable molecular-based method to identify and quantitatively analyze the infection progress of two fungi associated with grape berry rot $(G$. uvicola and $C$. acutatum) in artificially and naturally infected grapevine tissues. The ability of the technique to detect both pathogens simultaneously on the same plant tissue was also determined.

\section{Materials and Methods}

Fungal isolates. In total, 32 G. uvicola, 15 C. acutatum, and 9 isolates of other fungal species were isolated from vineyards in eastern Australia (Table 1). Pure cultures of single spore isolates were established according to Steel et al. (28) and representative isolates maintained in a collection at the National Wine and Grape Industry Centre (Wagga Wagga, NSW, Australia), and deposited in the Australian Scientific Collection Unit (Industry \& Investment NSW, Orange, Australia).

For the in vitro and field inoculation studies, mixtures of either G. uvicola DAR77258, DAR77260, and DAR77270 or C. acutatum DAR75574, DAR77283, and DAR77284 (Table 1) isolates were utilized. Mycelia and conidia were collected from 2-week-old cultures by adding $20 \mathrm{ml}$ of sterile water to the petri dish and gently scraping the surface of the colony with a scalpel blade. Mycelial fragments were removed by filtration through a double layer of sterile cheesecloth. Conidia were counted using a hemacytometer and the concentration adjusted to $10^{5} \mathrm{ml}^{-1}$ of conidia. Uninoculated controls were treated with an equivalent volume of sterile water.

Greenhouse inoculations. Inflorescences of disease-free 3-yearold greenhouse-grown Vitis vinifera (cv. Chardonnay) grapevines, maintained in natural daylight with daily irrigation and temperatures ranging between 15 and $30^{\circ} \mathrm{C}$, were inoculated by dipping them in suspensions of either G. uvicola or C. acutatum conidia at 
$10^{5} \mathrm{ml}^{-1}$. Two inflorescences were collected at $0,4,8,16,24,48$, $72,96,120,144,168$, and $192 \mathrm{~h}$ postinoculation. Ten flowers per inflorescence were surface sterilized in $1 \%$ bleach (active ingredient: $1.0 \%$ [wt/vol] sodium hypochlorite, Biolab) and $0.05 \%$ Tween 80 for $2 \mathrm{~min}$ and rinsed three times with sterile water, and the presence (or absence) of the bunch rot pathogens was verified on dichloran Rose Bengal chloramphenicol agar (DRBC; agar base, chloramphenicol media supplement; Oxoid Australia Pty Ltd.) followed by subsequent subculturing onto potato dextrose agar
(PDA; BD, Becton, Dickinson and Company) and microscopic analyzes. Results were expressed as mean percentage of infected flowers. The remaining parts of the inflorescences were analyzed by real-time PCR as each whole individual inflorescence was treated as an independent sample.

Field material and inoculations. A vineyard in the Hunter Valley, NSW, situated $200 \mathrm{~km}$ north of Sydney and prone to bunch rot diseases, was chosen to perform the field trials. The experimental site, elevation $56 \mathrm{~m}$, consisted of approximately 20 -year-old drip-

Table 1. Fungal isolates included in this study

\begin{tabular}{|c|c|c|c|c|}
\hline Species, isolate & Geographic origin & Date of isolation & Cultivar & Host tissue \\
\hline \multicolumn{5}{|l|}{ Greeneria uvicola } \\
\hline DAR77258 & Upper Hunter Valley, NSW & 2002 & Chardonnay & Berry \\
\hline DAR77259 & Hastings Valley, NSW & 2004 & Chambourcin & Berry \\
\hline DAR77260 & Hastings Valley, NSW & 2004 & Chardonnay & Berry \\
\hline DAR77261 & Hastings Valley, NSW & 2004 & Chambourcin & Berry \\
\hline DAR77262 & Hastings Valley, NSW & 2004 & Cabernet Sauvignon & Berry \\
\hline DAR77263 & Upper Hunter Valley, NSW & 2004 & Chardonnay & Berry \\
\hline DAR77264 & Upper Hunter Valley, NSW & 2004 & Chardonnay & Berry \\
\hline DAR77265 & Upper Hunter Valley, NSW & 2004 & Chardonnay & Berry \\
\hline DAR77266 & Upper Hunter Valley, NSW & 2004 & Chardonnay & Berry \\
\hline DAR77267 & Upper Hunter Valley, NSW & 2004 & Chardonnay & Berry \\
\hline DAR77268 & Upper Hunter Valley, NSW & 2004 & Chardonnay & Berry \\
\hline DAR77269 & Upper Hunter Valley, NSW & 2004 & Chardonnay & Berry \\
\hline DAR77270 & Upper Hunter Valley, NSW & 2004 & Chardonnay & Berry \\
\hline DAR77271 & Upper Hunter Valley, NSW & 2004 & Cabernet Sauvignon & Berry \\
\hline DAR77272 & Upper Hunter Valley, NSW & 2004 & Cabernet Sauvignon & Berry \\
\hline DAR77273 & Upper Hunter Valley, NSW & 2004 & Cabernet Sauvignon & Berry \\
\hline DAR77274 & Upper Hunter Valley, NSW & 2004 & Cabernet Sauvignon & Berry \\
\hline DAR77275 & Upper Hunter Valley, NSW & 2004 & Chardonnay & Berry \\
\hline DAR77276 & Upper Hunter Valley, NSW & 2004 & Chardonnay & Berry \\
\hline DAR77277 & Upper Hunter Valley, NSW & 2004 & Chardonnay & Berry \\
\hline DAR77278 & Upper Hunter Valley, NSW & 2004 & Chardonnay & Berry \\
\hline DAR77279 & Upper Hunter Valley, NSW & 2004 & Chardonnay & Berry \\
\hline DAR77280 & Upper Hunter Valley, NSW & 2004 & Chardonnay & Berry \\
\hline DAR77281 & Upper Hunter Valley, NSW & 2004 & Chardonnay & Berry \\
\hline MA231 ${ }^{\mathrm{a}}$ & Lower Hunter Valley, NSW & 2006 & Shiraz & Wood \\
\hline MAC11 ${ }^{\mathrm{a}}$ & Lower Hunter Valley, NSW & 2006 & Chardonnay & Wood \\
\hline MD25a & Lower Hunter Valley, NSW & 2006 & Semillon & Wood \\
\hline MD53 $^{\mathrm{a}}$ & Lower Hunter Valley, NSW & 2006 & Semillon & Wood \\
\hline MF322a & Upper Hunter Valley, NSW & 2006 & Chardonnay & Wood \\
\hline MF522a & Upper Hunter Valley, NSW & 2006 & Chardonnay & Wood \\
\hline MG53 $^{\mathrm{a}}$ & Upper Hunter Valley, NSW & 2006 & Cabernet Sauvignon & Wood \\
\hline MG55 & Upper Hunter Valley, NSW & 2006 & Cabernet Sauvignon & Wood \\
\hline \multicolumn{5}{|c|}{ Colletotrichum acutatum $^{\mathrm{b}}$} \\
\hline DAR75574 II & Hastings Valley, NSW & 2000 & Cabernet Sauvignon & Berry \\
\hline DAR77283 I & Upper Hunter Valley, NSW & 2002 & Cabernet Sauvignon & Berry \\
\hline DAR77284 III & Murgon, QLD & 2002 & Semillon & Berry \\
\hline B004 II & Hastings Valley, NSW & 2009 & Chardonnay & Berry \\
\hline B019 II & Hastings Valley, NSW & 2009 & Chardonnay & Berry \\
\hline B024 I & Hastings Valley, NSW & 2009 & Chardonnay & Berry \\
\hline B030 III & Hastings Valley, NSW & 2009 & Chardonnay & Berry \\
\hline B033 II & Hastings Valley, NSW & 2009 & Chardonnay & Berry \\
\hline B069 II & Hastings Valley, NSW & 2009 & Shiraz & Berry \\
\hline B111 III & Hastings Valley, NSW & 2009 & Cabernet Sauvignon & Berry \\
\hline B138 I & Hastings Valley, NSW & 2009 & Cabernet Sauvignon & Berry \\
\hline B140 I & Hastings Valley, NSW & 2009 & Cabernet Sauvignon & Berry \\
\hline B143 II & Hastings Valley, NSW & 2009 & Cabernet Sauvignon & Berry \\
\hline B146 III & Hastings Valley, NSW & 2009 & Cabernet Sauvignon & Berry \\
\hline L038 II & Hastings Valley, NSW & 2009 & Chardonnay & Leaves \\
\hline \multicolumn{5}{|c|}{ Colletotrichum gloeosporioides } \\
\hline B015 & Hastings Valley, NSW & 2009 & Chardonnay & Berry \\
\hline B022 & Hastings Valley, NSW & 2009 & Chardonnay & Berry \\
\hline B045 & Hastings Valley, NSW & 2009 & Chardonnay & Berry \\
\hline B084 & Hastings Valley, NSW & 2009 & Shiraz & Berry \\
\hline B090 & Hastings Valley, NSW & 2009 & Shiraz & Berry \\
\hline B148 & Hastings Valley, NSW & 2009 & Cabernet Sauvignon & Berry \\
\hline \multicolumn{5}{|l|}{ Botrytis cinerea } \\
\hline TN50 & Hunter Valley, NSW & 1988 & Chardonnay & Berry \\
\hline Phomopsis spp. & Upper Hunter Valley, NSW & 2009 & Unknown & Berry \\
\hline Erysiphe necator & Wagga Wagga, NSW & 2009 & Semillon & Leaves \\
\hline
\end{tabular}

${ }^{a}$ Kindly provided by Dr. Wayne Pitt and Yu Qiu (National Wine \& Grape Industry Centre, Charles Sturt University). Fungi were isolated and cultured as described by Pitt et al. (22).

${ }^{\mathrm{b}}$ Isolates were divided into three subgroups (I, II, and III) based on their sequence. 
irrigated own-rooted $V$. vinifera (cv. Chardonnay). The vines were grown on Pokolbin series Chocolate tending to Red Podzolic soil (as per description in "Soil Landscape of the Singleton 1:250 000 sheet" published by the Soil Conservation Service of New South Wales) at a row spacing of $3.0 \mathrm{~m}$ and vine spacing of $1.4 \mathrm{~m}$. The row alignment was north to south. Ten inflorescences were inoculated by applying approximately $800 \mu \mathrm{l}$ of inoculum (i.e., $0.8 \times 10^{5}$ conidia) with a hand sprayer and collected $24 \mathrm{~h}$ later. Ten flowers per inflorescence were plated on DRBC agar and analyzed as described in the section "Greenhouse inoculations." Mature berries were inoculated in the Hunter Valley as per the inoculation of inflorescences and 10 bunches collected $24 \mathrm{~h}$ later. Ten berries per bunch were surface sterilized, plated on DRBC, and analyzed as described earlier. Asymptomatic inflorescences and berries were also collected and analyzed in the same way as the artificially infected material. Results were expressed as mean percentage of infected flowers or berries. Real-time PCR studies were performed on two inflorescences or two berries.

In vitro inoculations. Mature berries without visible disease symptoms were collected from greenhouse facilities and from the Charles Sturt University vineyard (Wagga Wagga, NSW, Australia), a region free of G. uvicola and C. acutatum. Berries were surface sterilized and placed in sterile 24-well microplates (IWAKI brand; Asahi Glass Co., Japan) containing $20 \mathrm{ml}$ of water surrounding the wells to maintain high humidity. Each berry was inoculated with conidia at $10^{3} \mathrm{ml}^{-1}$ and incubated at $25^{\circ} \mathrm{C}$ in the dark. Two berries were analyzed by real-time PCR at $0,4,8,16$, $24,48,72,96,120,144,168$, and $192 \mathrm{~h}$ postinoculation.

DNA extraction, PCR amplification, and sequencing. Fungal DNA was extracted as described by Pitt et al. (22) with minor modifications. In brief, colonized agar plugs of each isolate were transferred to $50-\mathrm{ml}$ Falcon tubes containing $20 \mathrm{ml}$ of potato dextrose broth (Oxoid). Broth cultures were incubated on a Sartorius orbital shaker at $90 \mathrm{rpm}$ for 6 days at $25^{\circ} \mathrm{C}$ in the dark. Mycelia were harvested by gradient filtration on a $110-\mathrm{mm}$ filter paper and lyophilized, and DNA was extracted with the DNeasy Plant Mini Kit (Qiagen) following the manufacturer's instructions. DNA was extracted directly from inflorescences and skin peels of mature berries without prior surface sterilization. Each inflorescence or berry was treated as an individual sample. Approximately $100 \mathrm{mg}$ of each sample was ground to a powder in liquid nitrogen and the DNA extracted using the DNeasy Plant Mini Kit. A protocol for DNA extraction from spores was optimized. An average of $3 \times 10^{7}$ spores $/ \mathrm{ml}$ was collected from fungal isolates grown on PDA agar into either AP1 buffer from the Qiagen DNeasy Plant Mini Kit or water. Spore suspensions were adjusted to $10^{5} \mathrm{ml}^{-1}$ with either AP1 buffer or water according to the method for harvesting conidia. DNA was extracted from $100 \mu \mathrm{l}\left(10^{4} \mathrm{ml}^{-1}\right)$ of individual spore sus- pension with the DNeasy Plant Mini Kit. Four different approaches were investigated to find the optimal procedure for DNA extraction from spores: the spores were (i) heated at $95^{\circ} \mathrm{C}$ for $10 \mathrm{~min}$; (ii) microwaved three times at maximum power $(1,000 \mathrm{~W})$ for $20 \mathrm{~s}$; or (iii) frozen at $-80^{\circ} \mathrm{C}$ for $20 \mathrm{~min}$ and thawed, three times; or (iv) 1 $\mu \mathrm{l}$ of spore suspension was used directly for real-time PCR. DNA was dissolved in $100 \mu \mathrm{l}$ of sterile water and $1 \mu \mathrm{l}$ was used for realtime PCR.

Molecular identifications of the pure cultures on PDA were achieved by amplification and comparison of the rDNA ITS regions (ITS1, 5.8S, and ITS2) using the standard oligonucleotides ITS1 and ITS4 (29) (Fig. 1). Amplification was performed in 50- $\mu$ l reactions containing $10 \mathrm{ng}$ of template DNA, $1 \mathrm{U}$ of Taq polymerase (New England BioLabs), 1× New England BioLabs standard buffer, $250 \mu \mathrm{M}$ dNTPs, and 10 pmol of each primer. PCR amplification was conducted in a C1000 Thermocycler (Bio-Rad) with an initial step of 2 min at $94^{\circ} \mathrm{C}$, followed by 40 cycles of $94^{\circ} \mathrm{C}$ for $30 \mathrm{~s}, 55^{\circ} \mathrm{C}$ for $45 \mathrm{~s}$, and $72^{\circ} \mathrm{C}$ for $90 \mathrm{~s}$. DNA samples and PCR products were visualized on $1 \%$ agarose gels stained with ethidium bromide. PCR products were purified using the QIAquick PCR purification kit (Qiagen) following the manufacturer's instructions to remove excess primers and nucleotides. ITS regions were sequenced in both directions with the ITS1 and ITS4 primers by the Australian Genome Research Facility (University of Queensland). Multiple sequence alignments, contig assembly, comparison of nucleotide sequences, and primer design were performed with DNASTAR software (DNASTAR Inc.; www.dnastar.com). Confirmation of G. uvicola and C. acutatum was achieved by comparison of the identified ITS sequences to those available in GenBank. Nucleotide homology searches were performed with the BLAST nucleotide program (http://www.ncbi.nlm.nih.gov).

Real-time PCR. Specificity of the PCR primers used in this study was tested on all of the fungi listed in Table 1. Real-time PCR amplification and cycling parameters were performed according to the SYBR Green JumpStart Taq ReadyMix Kit (Sigma-Aldrich) using a Corbett Rotor-Gene 6000 5-plex Thermocycler (Qiagen). The PCR reaction contained either $1 \mu \mathrm{l}$ of spore DNA or an appropriate amount of template DNA (see Results, Real-time PCR assay), 5 pmol each primer, and $1 \times$ SYBR Green JumpStart Taq ReadyMix in a final volume of $25 \mu$ l. PCR conditions were optimized for annealing temperature and DNA dilutions. The final profile was: initial denaturation for $2 \mathrm{~min}$ at $94^{\circ} \mathrm{C}$, followed by 40 cycles of $94^{\circ} \mathrm{C}$ for $30 \mathrm{~s}$, annealing temperature of $60^{\circ} \mathrm{C}$ for $30 \mathrm{~s}$, and extension at $72^{\circ} \mathrm{C}$ for $60 \mathrm{~s}$. Visualization of the SYBR Green was achieved by a melting ramp from 62 to $94^{\circ} \mathrm{C}$, rising $1{ }^{\circ} \mathrm{C}$ each step, with a hold for $90 \mathrm{~s}$ for premelt on the first step and $5 \mathrm{~s}$ for each step afterward. All real-time PCRs were repeated twice for the duplicate fungal or plant samples and each inoculation time

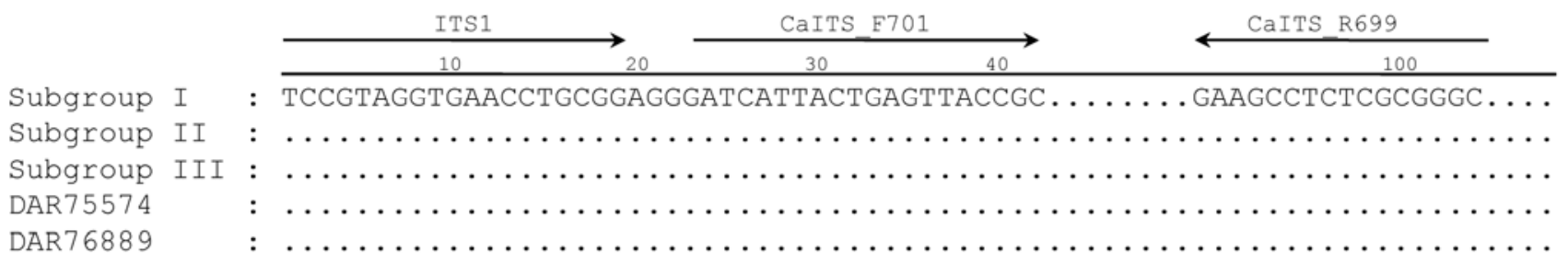

ITS 4

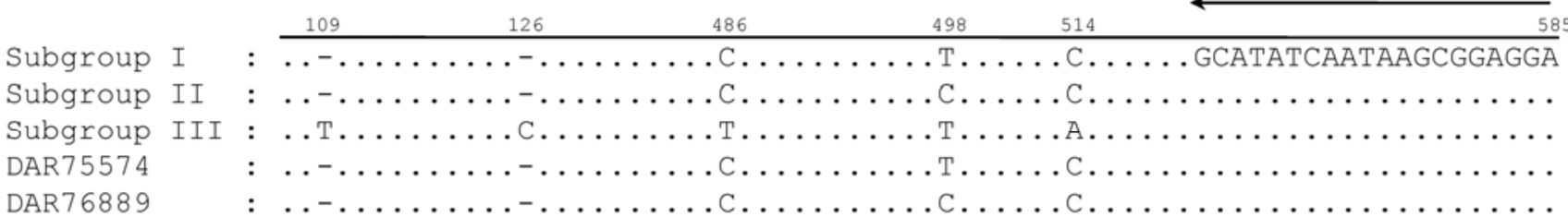

Fig. 1. Multiple sequence alignment of Colletotrichum acutatum isolates from three subgroups and the primers used to amplify them for sequencing (internal transcribed spacer [ITS]1 and ITS4) and reverse-transcription polymerase chain reaction (CalTS_F701 and CalTS_R699). The three subgroups differ at positions 109, 126, 486, 498, and 514. Subgroup I sequence was identical to DAR75574 and subgroup II to DAR76889; subgroup III was >99\% homologous to subgroups I and II. Symbols: "." represents identical nucleotides and "-" indicates nucleotides not present. 
point. Control reactions contained water instead of fungal or plant DNA. The data was normalized as previously described (23) using the primer pair UbiF, 5'-ACTCTCACCGGAAAGACCATC-3' (forward), and UbiR, 5'-TCACGTTGTCAATGGTGTCAG-3' (reverse), derived from the Arabidopsis thaliana polyubiquitin 10 (NM_178969.2; ubq10). Comparison of relative DNA concentrations was determined using the $2^{-\Delta \Delta \mathrm{CT}}$ method (17). $\Delta \Delta \mathrm{C}_{\mathrm{T}}=$ $\left(\mathrm{C}_{\mathrm{T} \text {,target }}-\mathrm{C}_{\mathrm{T} \text {,ubq10 }}\right)$, where $\mathrm{C}_{\mathrm{T}}$ is the threshold cycle which represents the PCR cycle at which the copy number passes the fixed threshold and can be first detected.

To check whether an excess of plant DNA could inhibit the amplification of fungal DNA, serial dilutions were performed as follows: the amount of plant DNA was maintained constant $(15 \mathrm{ng})$ while fungal DNA was decreased to achieve 10-fold dilutions.

\section{Results}

Extraction of genomic DNA from spores, fungi, and plant material. The highest level of DNA detection was achieved when spores were frozen at $-80^{\circ} \mathrm{C}$ and thawed repeatedly (data not shown) and this approach was used further in the study. DNA extracted from pure fungal isolates as well as from all artificially and naturally infected inflorescences, mature berries, and healthy plant tissue yielded approximately $50 \mathrm{ng}$ of DNA per $1 \mathrm{mg}$ of dried fungal tissue or $5 \mathrm{mg}$ of wet plant sample.

ITS sequencing, design, and validation of specific primers for $\boldsymbol{G}$. uvicola and $\boldsymbol{C}$. acutatum. The rDNA 58S ITS was amplified using the universal primers ITS1 and ITS4. A single PCR fragment of approximately $600 \mathrm{bp}$ was produced for all G. uvicola isolates which, after sequencing, was established to be $599 \mathrm{bp}$ in length. Multiple alignment of all amplicons revealed that all isolates were $100 \%$ identical at their ITS region. A DNA sequence from this study was submitted to the National Center for Biotechnology Information (NCBI; www.ncbi.nlm.nih.gov, ref no.
GU907101), and currently represents the only sequence of the ITS region of this fungus in NCBI. Amplification of $C$. acutatum isolates generated two fragments of 583 and $585 \mathrm{bp}$. Three variations of $C$. acutatum were identified because two had the same size of $583 \mathrm{bp}$ and one of $585 \mathrm{bp}$. The C. acutatum isolates were placed in three subgroups (Fig. 1). A comparison of homology to the C. acutatum sequences in GenBank revealed that the highest nucleotide sequence identity was shared with DAR75574 and DAR76889, described by Whitelaw-Weckert et al. (30).

Three pairs of primers were designed for G. uvicola and two for C. acutatum using the DNASTAR software; the primers were compared with sequences available at NCBI to insure that they would not amplify DNA from other organisms (data not shown). The CaITS_F701/CaITS_R699 and CaITS_F701/CaITS_R815 primer pairs developed by Debode and co-workers (8) to study C. $a c u$ tatum on strawberries were also tested in this study because they did not coincide with the region of nuclear mismatches between the different isolates (Fig. 1). Based on melting curve analyses, the primer pairs GuF2b (5'-TCTGAACGTATCTCTTCTGAG-3') and GuR2 (5'-TAAGTCAACCTAAGCGAGAAG-3') designed in this study and CaITS_F701/CaITS_R699 did not result in the production of nonspecific bands when tested against genomic fungal DNA of pure cultures of all isolates presented in Table 1 and, therefore, were chosen for further analyses.

Real-time PCR assay. Real-time PCR was first performed on fungal genomic DNA to establish the procedure. Serial 1:10 DNA dilutions of $2 \mathrm{ng}$ of DNA were used to determine the sensitivity of the method. The standard curves obtained showed a linear correlation between input DNA and $\mathrm{C}_{\mathrm{T}}$ with $r^{2}$ of 0.9916 and 0.9964 for G. uvicola and C. acutatum, respectively (Fig. 2). Fluorescence remained below threshold values for the water controls and nontarget species. Agarose gel electrophoresis of the real-time PCR products showed a positive correlation between the fluorescence and

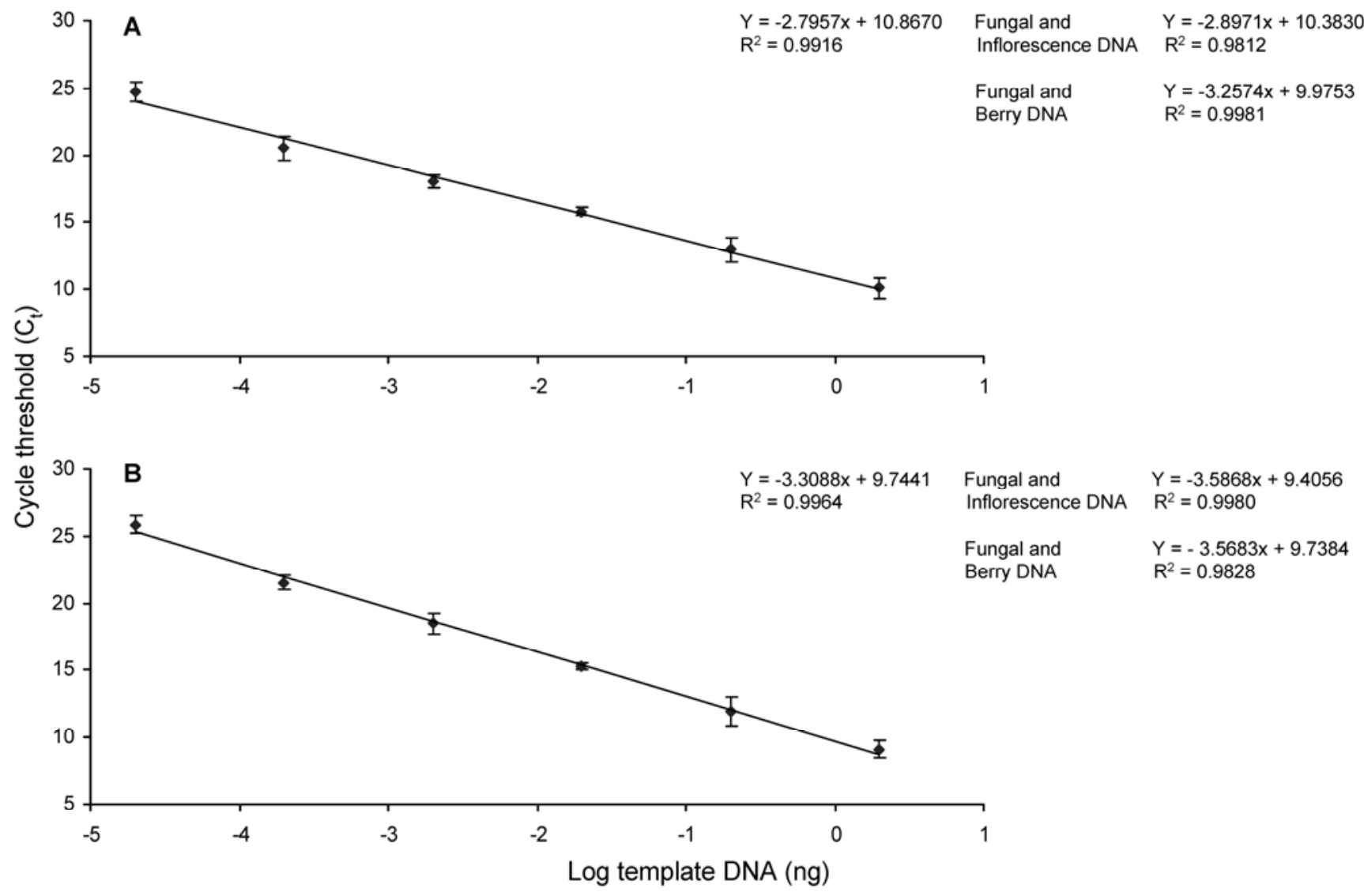

Fig. 2. Linear relationship between cycle threshold $\left(C_{T}\right)$ and fungal DNA concentrations of $\mathbf{A}$, Greeneria uvicola and $\mathbf{B}$, Colletotrichum acutatum amplified using reversetranscription polymerase chain reaction (RT-PCR). $C_{\top} S$ were plotted against the log of 10 -fold serial dilutions of known genomic DNA from 20 fg to 2 ng. $C_{T}$ values shown are the mean of three replications; error bars represent standard deviations. The same dilutions were tested in the presence of flower and berry DNA (15 ng). Because the lines for the three sets of data are overlapping, the $R^{2}$ equations when the sensitivity of RT-PCR was tested in the presence of flower and berry DNA are presented separately. 
amplification of the expected DNA fragments. In the dilution series of both $G$. uvicola and C. acutatum, the practical detection limit of the real-time PCR method was fungal genomic DNA at $20 \mathrm{fg}^{-1}{ }^{-1}$. The same experiment was performed to study whether grape DNA inhibits the sensitivity of the real-time PCR. It was found that the same fungal DNA quantities were detected in the presence of both flower and berry DNA (Fig. 2). The standard curves obtained revealed high precision and reproducibility between the different assays, as indicated by correlation coefficients $\left(R^{2}\right)=0.9912$ to 0.9981 for $G$. uvicola and $R^{2}=0.9828$ to 0.9980 for $C$. acutatum. Serial dilution of spore DNA in water allowed detection of approximately 10 conidia with both $\mathrm{GuF} 2 \mathrm{~b} / \mathrm{GuR} 2\left(R^{2}=0.9855\right)$ and CaITS_F701/CaITS_R699 $\left(R^{2}=0.9971\right)$. No amplification was obtained from DNA extracted from healthy grape tissue or from the other fungal species examined (Table 1).

Monitoring fungal development on plant tissues. First visible symptoms of Bitter Rot and Ripe Rot development on berries in vitro included discharge of juice combined with cracking of the skin, typically observed 2 to 4 days after inoculation. Black or orange spore masses were visible 3 to 5 days postinoculation $(G$. uvicola and $C$. acutatum, respectively). Conventional plating detected G. uvicola and C. acutatum in 40 and $72 \%$ of all artificially infected flowers, respectively, and $100 \%$ on mature berries. Realtime PCR was able to detect both fungi on all artificially inoculated plant material (inflorescences and berries). The two pathogens were not detected by either method on noninoculated inflorescences from the Hunter Valley collected in 2009, a viticultural region prone to bunch rot diseases, but were detected on asymptomatic mature berries later in the season.

Fungal growth was quantified by real-time PCR at different time points postinoculation. The relative quantities of grape genomic DNA were analyzed as template DNA samples and equalized, and calculations were performed based on amplification with the UbiF and UbiR primers. Differences in amplification intensity were not observed for flowers. In contrast, a gradual increase in the amplification intensity was detected from 0 to 8 days postinoculation on mature berries in vitro (Fig. 3). Real-time PCR was used to detect the presence or absence of G. uvicola or C. acutatum DNA from 50 randomly sampled and asymptomatic mature berries from the

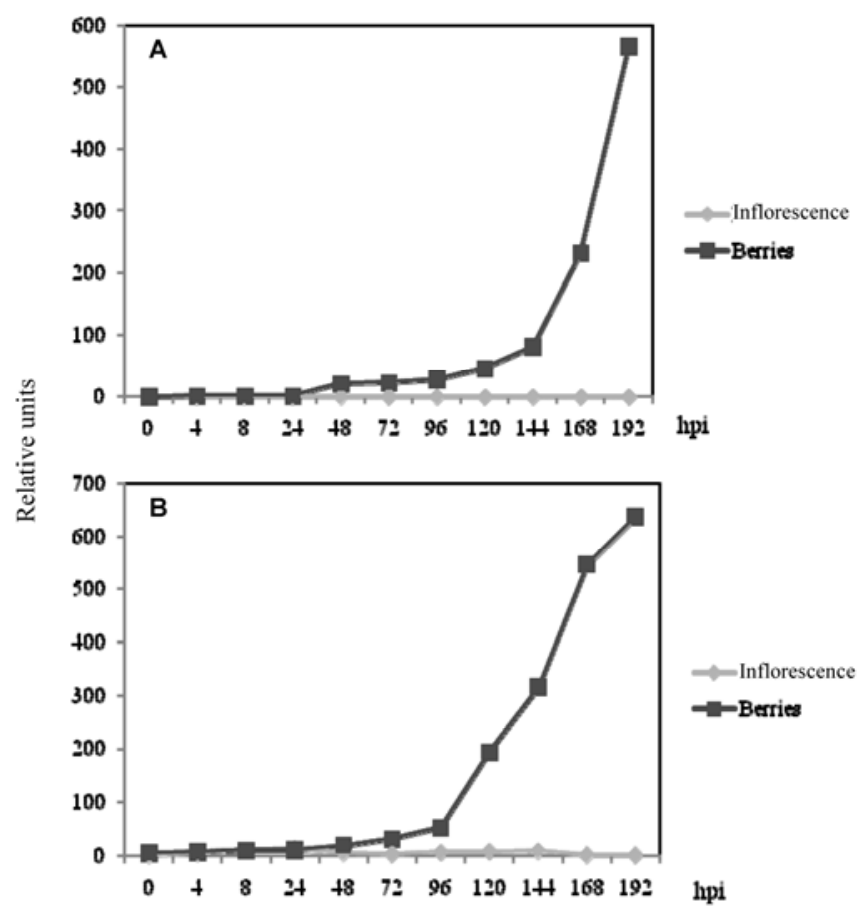

Fig. 3. Development of A, Greeneria uvicola and B, Colletotrichum acutatum on inflorescences and physiologically mature berries at different time points (hours post inoculation [hpi]). Standard deviations were negligibly small and are not presented on the chart for better visualization.
Hunter Valley. Conventional plating methods detected G. uvicola and $C$. acutatum from 5 and $55 \%$ of mature berries, respectively, whereas real-time PCR detected G. uvicola and C. acutatum from 20 and $76 \%$ of mature berries, respectively. Real-time PCR was able to simultaneously detect both pathogens on one berry in $13 \%$ of the berries.

\section{Discussion}

A molecular method was evaluated for the fast and precise detection and quantification of G. uvicola and C. acutatum in artificially and naturally infected plant material from grapevine. Comparison of the ITS sequences successfully confirmed the accuracy of morphological fungal identification and provided information for phylogenetic analyzes as well as design of species-specific primers. To the best of our knowledge, there is no literature concerning the genetic variability of G. uvicola. This study revealed uniformity among all the Australian isolates of $G$. uvicola analyzed in this study and a high similarity between $C$. acutatum isolates based on their ITS sequence. The $C$. acutatum isolates analyzed in this study were positioned in three subgroups: 1 and 2, which were identical to isolates DAR75574 and DAR76889, respectively; and group 3, which was $>99 \%$ homologous to DAR75574 and DAR76889, placing them in group A9, containing all Australian $C$. acutatum isolates from subtropical wine grape-growing regions (30). It might be speculated that the lack of genetic diversity within the different $G$. uvicola and $C$. acutatum isolates is due to both the absence of sexual reproduction of these species and to the relatively small geographical area from which the isolates were collected.

ITS regions of the rDNA have been widely used for phylogenetic studies and diagnostic assay development $(5,19,26)$. These regions are highly stable, can be easily amplified and sequenced, occur in multiple copies, and possess conserved as well as variable sequences (2,29). ITS-based sequencing and ITS-based primers have been reported and successfully used to identify and analyze a number of fungal plant pathogens, including $C$. acutatum $(8,20$, 21). However, the standard sequencing method is time consuming and tedious whereas real-time PCR offers a rapid and simple method with increased sensitivity. No post-PCR processing and sequencing is necessary because quantification of DNA is achieved based on the $\mathrm{C}_{\mathrm{T}}$ value measured during the PCR amplification. The real-time PCR method allowed the detection of as little as $20 \mathrm{fg}$ of genomic DNA and 10 spores for G. uvicola and C. acutatum. These thresholds are lower than those detected for $C$. acutatum by nested PCR (20) and TaqMan real-time PCR (8). In addition, the SYBRGreen technology was employed in this study because it is less labor intensive, has comparatively low operational costs, has higher sensitivity, and provides reliable quantitative results compared with nested PCR and TaqMan $(8,26)$.

One of the limitations when using PCR techniques is the preparation of good-quality nucleic acid that is free of PCR inhibitors. There are a number of PCR inhibitors in grape tissue, particularly in the flesh of mature berries, that affect DNA amplification in conventional PCR (24). The DNeasy Plant Kit (Qiagen) was used to extract grape DNA because it is considered the best method for DNA extraction for amplification of pathogens from "difficult" samples $(9,15,16,24)$. Parikka and Lemmetty (21) have added polyvinylpolypyrrolidone (PVPP) to the extraction buffer of the kit but this was not used in the present study because there was no difference between the sensitivity of the method when the target DNA was quantified based on serial dilutions in water in the presence of both flower and berry DNA, and also because DNA was extracted from berry skins rather than from the whole berries. Another reason for the omission of PVPP was the fact that the fungi develop on the surface of the berry.

In the current study, modified extraction methods were used that allowed rapid and simple DNA extraction from up to 30 samples of spores and grape tissues within 2 to $3 \mathrm{~h}$, without the use of toxic reagents such as phenol, chloroform, or $\beta$-mercaptoethanol. Although the simple commercially available extraction method used was found to be successful for flowers and berries, it is likely that 
the method will have to be adapted for extraction of the fungal DNA from wood and other tissues.

Grape berries do not always show clear symptoms of either bitter rot or ripe rot. Although G. uvicola frequently presents itself as concentric black rings of sporulation on mature grape berries, these symptoms might be confused with those produced by other bunchrotting fungi that produce black spores (e.g., Alternaria spp., Phomopsis viticola, and so on). Although $C$. acutatum produces orange masses of spores on the berries, these are only visible in the latter stages of infection. Furthermore, ripe rot of grape can also be caused by other Colletotrichum spp. (7). Similar symptoms are observed on grape berries, making morphological differentiation difficult. In a bunch rot complex, infection levels may be low or a mixture of organisms can be present and clear symptoms may not be observed (28). In these cases, a small amount of plant tissue or pure sample of spores can be collected for direct PCR analyzes. If a more precise detection (determination) of species belonging to the Colletotrichum complex is desired, primers from other genes $(1,14)$ can be designed and used with the protocol demonstrated in this study.

Conventional isolation of G. uvicola and C. acutatum from plant material on artificial media was less sensitive than detection with real-time PCR. G. uvicola and C. acutatum could not be isolated from more than half of the artificially inoculated flowers and mature berries yet all these samples showed positive PCR amplification of fungal DNA. It might be speculated that some PCR products could have been amplified from nonviable pathogen propagules (21).

In conclusion, a real-time PCR method was developed to reliably identify and quantify two fungal species, G. uvicola and $C$. acutatum, associated with bunch rot of grape, including three $C$. acutatum intraspecific subgroups, under controlled and natural conditions. The results demonstrate that this method is highly specific and sensitive. Amplification was achieved immediately after inoculation with relatively small amounts of DNA template present in the conidial and mycelial inoculum. Application of the method demonstrated that both $G$. uvicola and $C$. acutatum infect flowers but remain quiescent. Their infection progress could be monitored through real-time PCR during berry ripening. The method can now be used in epidemiological studies to advance the understanding of the dynamics of these and other bunch rot pathogens in the vineyard. In future, real-time PCR, applied as a diagnostic tool, may also be used to inform grape producers in regard to the timing of fungicides or harvest to avoid fruit losses.

\section{Acknowledgments}

This work was conducted within the Winegrowing Futures Program-a joint initiative of the Grape and Wine Research and Development Corporation (GWRDC) and the National Wine and Grape Industry Centre. We thank R. Wood and J. Hardie for critical review of the manuscript; C. Haywood (New South Wales Industry and Investment) for organizing and managing the experimental sites; R. Huang, E. Simova, L. Greer, and S. Greer for technical assistance; and the grapegrowers and winemakers of New South Wales who provided access to their properties and participated in this study.

\section{Literature Cited}

1. Cai, L., Hyde, K. D., Taylor, P. W. J., Weir, B. S., Waller, J. M., Abang, M. M., Zhang, J. Z., Yang, Y. L., Phoulivong, S., Liu, Z. Y., Prihastuti, H., Shivas, R. G., McKenzie, E. H. C., and Johnston, P. R. A polyphasic approach for studying Colletotrichum. Fungal Divers. 39:183-204.

2. Campanile, G., Schena, L., and Luisi, N. 2008. Real-time PCR identification and detection of Fuscoporia torulosa in Quercus ilex. Plant Pathol. 57:76-83.

3. Causin, R., Scopel, C., Grendene, A., and Montecchio, L. 2005. An improved method for the detection of Phytophthora cactorum (L.C.) Schröeter in infected plant tissues using SCAR markers. J. Plant Pathol. 87:25-35.

4. Chilvers, M. I., du Toit, L. J., Akamatsu, H., and Peever T. L. 2007. A realtime, quantitative PCR seed assay for Botrytis spp. that cause neck rot of onion. Plant Dis. 91:599-608.

5. Cooke, D. E. L., Schena, L., and Cacciola, S.O. 2007. Tools to detect, identify and monitor Phytophthora species in natural ecosystems. J. Plant Pathol. 89:145-160.

6. Cullen, D. W., Toth, I. K., Boonham, N., Walsh, K., Barker, I., and Lees, A. K. 2007. Development and validation of conventional and quantitative polymerase chain reaction assays for the detection of Storage Rot potato pathogens, Phytophthora erythroseptica, Pythium ultimum and Phoma foveata. J.
Phytopathol. 155:309-315.

7. Daykin, M. E., and Milholland, R. D. 1984. Ripe rot of muscadine grape caused by Colletotrichum gloeosporioides and its control. Phytopathology 74:710-714.

8. Debode, J., Van Hemelrijck, W., Baeyen, S., Creemers, P., Heungens, K., and Maes, M. 2009. Quantitative detection and monitoring of Colletotrichum acutatum in strawberry leaves using RT-PCR. Plant Pathol. 58:504-514.

9. Fatmi, M., Damsteegt, V. D., and Schaad, N. W. 2005. A combined agarabsorption and BIO-PCR assay for rapid, sensitive detection of Xylella fastidiosa in grape and citrus. Plant Pathol. 54:1-7.

10. Gayoso, C., de Ilárduya, O. M., Pomar, F., and de Cáceres, F. M. 2007. Assessment of real-time PCR as a method for determining the presence of Verticillium dahliae in different Solanaceae cultivars. Eur. J. Plant Pathol. 118:199-209.

11. Guillemette, T., Iacomi-Vasilescu, B., and Simoneau, P. 2004. Conventional and real-time PCR-based assay for detecting pathogenic Alternaria brassicae in cruciferous seed. Plant Dis. 88:490-496.

12. Hayden, K. J., Rizzo, D., Tse, J., and Garbelotto, M. 2004. Detection and quantification of Phytophthora ramorum from California forests using a real-time polymerase chain reaction assay. Phytopathology 94:10751083.

13. Hughes, K. J. D., Tomlinson, J. A., Griffin, R. L., Boonham, N., Inman, A. J., and Lane, C.R. 2006. Development of a one-step real-time polymerase chain reaction assay for diagnosis of Phytophthora ramorum. Phytopathology 96:975-981.

14. Hyde, K. D., Cai, L., Cannon, P. F., Crouch, J. A., Crous, P. W., Damm, U., Goodwin, P. H., Chen, H., Johnston, P. R., Jones, E. B. G., Liu, Z. Y., McKenzie, E. H. C., Moriwaki, J., Noireung, P., Pennycook, S. R., Pfenning, L. H., Prihastuti, H., Sato, T., Shivas, R. G., Tan, Y. P., Taylor, P. W. J. Weir, B. S., Yang, Y. L., and Zhang, J. Z. 2009. A polyphasic approach for studying Colletotrichum. Fungal Divers. 39:147-182.

15. Li, W., Brlansky, R. H., and Hartung, J. S. 2006. Amplification of DNA of Xanthomonas axonopolis pv. citri from historic citrus canker herbarium specimens. J. Microbiol. Methods 65:237-246.

16. Li, W., Li, D., Twieg, E., Hartung, J. S., and Levy, L. 2008. Optimized quantification of unculturable Candidatus Liberibacter spp. in host plants using real-time PCR. Plant Dis. 92:854-861.

17. Livak, K. J., and Schmittgen, T. D. 2001. Analysis of relative gene expression data using real-time quantitative PCR and the $2^{-\Delta \Delta C T}$ method. Methods 25:402-408.

18. Meunier, M., and Steel, C. C. 2009. Effect of Colletotrichum acutatum ripe rot on the composition and sensory attributes of Cabernet Sauvignon grapes and wine. Aust. J. Grape Wine Res. 15:223-227.

19. Mumford, R., Boonham, N., Tomlinson, J., and Barker, I. 2006. Advances in molecular phytodiagnostics-new solutions for old problems. Eur. J. Plant Pathol. 116:1-19.

20. Nam, M. H., Pérez-Hernàndez, O. P., Kim, H. G., and Gleason, M. L. 2007. Development of a nested-PCR assay for detection of Colletotrichum acutatum in vitro. (Abstr.) Phytopathology 97:S82.

21. Parikka, P., and Lemmetty, A. 2004. Tracing latent infection of Colletotrichum acutatum on strawberry by PCR. Eur. J. Plant Pathol. 110:393-398.

22. Pitt, W. M., Huang, R., Steel, C. C., and Savocchia, S. 2010. Identification, distribution and current taxonomy of Botryosphaeriaceae species associated with grapevine decline in New South Wales and South Australia. Aust. J. Grape Wine Res. 16:258-271.

23. Samuelian, S. K., Camps, C., Kappel, C., Simova, E. P., Delrot, S., and Colova, V. M. 2009. Differential screening of overexpressed genes involved in flavonoid biosynthesis in North American native grapes: 'Noble' muscadinia var. and 'Cynthiana' aestivalis var. Plant Sci. 177:211-221.

24. Schaad, N. W., Opgenorth, D., and Gaush, P. 2002. Real-time polymerase chain reaction for one-hour on-site diagnosis of Pierce's disease of grape in early season asymptomatic vines. Phytopathology 92:721-728.

25. Schena, L., and Cooke, D. E. L. 2006. Assessing the potential of regions of the nuclear and mitochondrial genome to develop a 'molecular tool box' for the detection and characterization of Phytophthora species. J. Microbiol. Methods 67:70-85.

26. Schena, L., Nigro, F., Ippolito, A., and Gallitelli, D. 2004. Real-time quantitative PCR: a new technology to detect and study phytopathogenic and antagonistic fungi. Eur. J. Plant Pathol. 110:893-908.

27. Shivas, R. G., and Tan, Y. P. 2009. A taxonomic re-assessment of Colletotrichum acutatum, introducing $C$. floriniae comb. et stat. nov. and acutatum sp. nov. Fungal Divers. 39:111-122.

28. Steel, C. C., Greer, L. A., and Savocchia, S. 2007. Studies on Colletotrichum acutatum and Greeneria uvicola: two fungi associated with bunch rot of grapes in sub-tropical Australia. Aust. J. Grape Wine Res. 13:23-29.

29. White, T. J., Bruns, T. D., Lee, S., and Taylor, J. W. 1990. Amplification and direct sequencing of fungal ribosomal RNA genes for phylogenetics. Pages 315-322 in: PCR Protocols: A Guide to Methods and Applications. M. A. Innis, D. H. Gelfand, J. J. Sninsky, and T. J. White, eds. Academic Press, San Diego, CA

30. Whitelaw-Weckert, M. A., Curtin, S. J., Huang, R., Steel, C. C., Blanchard, C. L., and Roffey, P. E. 2007. Phylogenetic relationships and pathogenicity of Colletotrichum acutatum isolates from grape in subtropical Australia. Plant Pathol. 56:448-463. 